\title{
Radiation Dose Features and Solid Cancer Induction in Pediatric Computed Tomography
}

\author{
Ernest K.J. Pauwels ${ }^{a, b}$ Michel H. Bourguignon ${ }^{c, d}$ \\ ${ }^{\text {a } D e p a r t m e n t ~ o f ~ R a d i o l o g y, ~ L e i d e n ~ U n i v e r s i t y ~ M e d i c a l ~ C e n t e r, ~ L e i d e n, ~ T h e ~ N e t h e r l a n d s ; ~}{ }^{b}$ Department of \\ Nuclear Medicine, Pisa University Medical School, Pisa, Italy; ' Department of Biophysics, Université de Versailles Saint \\ Quentin en Yvelines, and d Autorité de Sureté Nucléaire, Paris, France
}

\section{Key Words}

Computed tomography $\cdot$ Radiation dose $\cdot$ Cancer

induction $\cdot$ Pediatrics $\cdot$ Cancer risk

\begin{abstract}
Over the past two decades technical advances and improvements have made computed tomography (CT) a valuable and essential tool in the array of diagnostic imaging modalities. CT uses ionizing radiation (X-rays) which may damage DNA and increase the risk of carcinogenesis. This is especially pertinent in pediatric $\mathrm{CT}$ as children are more radiosensitive and have a longer life expectancy than adults. The purpose of this paper is to review and elucidate the potential harmful effects of ionizing radiation in terms of solid cancer induction from pediatric CT scanning. In the light of scientific and technical developments, we will also discuss the possible strategies and ongoing efforts to reduce $\mathrm{CT}$ radiation exposure in pediatric patients. In this context, we will not ignore the fact that a well-justified CT scan may exceed its risk and have a favorable impact.
\end{abstract}

Copyright $\odot 2012$ S. Karger AG, Basel

E.K.J.P. wishes to dedicate this paper to Professor Dr. Ad van Voorthuisen, a worthy individual, supportive colleague, and visionary radiologist, on the occasion of his 80th birthday.

\section{KARGER}

Fax +4161306 1234

E-Mail karger@karger.ch

www.karger.com (c) 2012 S. Karger AG, Basel

1011-7571/12/0216-0508\$38.00/0

Accessible online at:

www.karger.com/mpp

\section{Introduction}

Over the past several decades, technical developments in computed tomography (CT) have provided advances in temporal and spatial resolution. This has resulted in shorter scanning time and thinner slice thicknesses. It has led to an increased number of diagnostic applications and number of scans per patient as well as an increase in the number of installed CT scanners worldwide. Indeed, in 2009 it was reported that every day more than 19,500 CT scans were performed in the USA [1]. Mettler et al. [2] reported in the same year that in 2006, 67 million CT scans were performed in the US, which accounted for $17 \%$ of the total number of medical imaging procedures. Hence, the growth of CT examinations is evident when compared with the number of CT scans in 1980-1982, which was estimated to be 2-3.5 million per year. This increased utilization of CT, however, comes with a price: the US per capita annual effective dose from CT has increased from $0.016 \mathrm{mSv}$ (1980-1982) to $1.47 \mathrm{mSv}$ (2006) [2]. Similarly, the per-capita annual effective dose from diagnostic imaging procedures has increased about a six fold from about $0.5-3.0 \mathrm{mSv}$, which implies that about half of the radiation exposure is due to CT scanning. Sadetsky [3] gathered data from the USA and Europe and demonstrated in 2007 that although CT scanning only constituted $5-10 \%$ of all imaging procedures, it contributed $40-67 \%$ of the total radiation burden. 
Ideally, the acquisition of CT images occurs according to standardized validated protocols endorsed by national and/or international professional organizations, enabling the demonstration and differentiation of abnormalities. However, there is a lack of standardization and a wide variation of acquisition parameters and dose variations for the same CT examination [4-6]. This is illustrated by the management of noise in the image. A proper image interpretation requires a noise level that is neither high nor low. Obviously, images with high noise levels, associated with low radiation intensity, may be nondiagnostic. Lower noise levels may be obtained by adjusting the grey scale of the area of interest, but image degradation may occur resulting in diagnostic inaccuracies. This noise-associated problem may be overcome by applying high levels of radiation intensity, which minimizes image noise and image quality. This approach, together with the rising number of CT scans, has raised concern for the lifelong risk of cancer induced by radiation exposure from CT imaging $[7,8]$. As children have a longer life expectancy than adults, pediatric studies may have long-term consequences. Moreover, the radiation sensitivity of children is higher than adults [9]. Their rapid growth is associated with a high rate of cell division, which is the most risky phase for induction of DNA damage. Besides, in children the biological process for the identification of mutated cells and the induction of repair mechanisms is not very effective yet. In this context, it is important to know that there were at least 6.5 million CT examinations performed on children in the US in 2006. This corresponds to about $10 \%$ of all CT examinations [10]. Consequently, in the early 2000s, both researchers and the Federal Drug Administration (FDA) called attention to the necessity of reducing the risk of radiation exposure from CT for pediatric patients $[11,12]$. The lifetime solid cancer risk estimates for those exposed as children might be a factor 2-3 times higher than the estimates for the general population [13]. In addition, a recent report demonstrates a statistically significant dose-related increase in the incidence of solid cancer for those exposed in the first 6 years of life, similar to the time of the atomic bombing in Japan. The relative risk of cancer, averaged for attained age (12-54 years), gender and dose categories is estimated to be 1.4 for those exposed in early childhood [14]. Likewise, the WHO has documented an increased incidence of thyroid cancer in irradiated children under 18 years of age following the Chernobyl accident (http://www.who. int/mediacentre/factsheets/fs303/en/index.html).

The purpose of this paper is to review and elucidate the potential harmful effects of ionizing radiation in terms of solid cancer induction from pediatric CT scanning. Based on scientific and technical developments, we will also discuss the possible strategies and ongoing efforts to reduce CT radiation exposures in pediatric patients. However, we should point out the fact that a welljustified CT scan could exceed the risk from exposure yet have a favorable clinical impact. First, however, we will give very brief descriptions of some basic principles of physics regarding CT imaging and units of radiation dose.

\section{Basic Principles of Medical CT}

Unlike ultrasound and magnetic resonance imaging (MRI), CT uses ionizing radiation. During a CT scan, a rotating X-ray source passes X-rays through a body part of the patient while often the table on which the patient lies moves in order to cover the part of the anatomy of interest. Opposite the X-ray source, a detector unit is mounted and both the source and the detector rotate around the patient in a circular way to produce crosssectional images. The transmitted X-rays are then converted into electrical signals that are collected from different angles and are reconstructed by specialized software (filtered backprojection and/or iterative reconstruction) to create a three-dimensional presentation of tissue densities relative to water in the body. Finally, this procedure results in artificial cross-sectional coupes ('slices') of the scanned volume. The slice thickness can be in the order of millimeters, thus providing a detailed set of slice-images. Modern technology allows for a complete rotation in less than $0.5 \mathrm{~s}$ and a complete reconstruction in tenths of a second. These characteristics have made CT a very valuable tool for high patient throughput and accurate diagnosis, longitudinal measurements of disease progression and monitoring of treatment.

\section{Dosimetric Units Used in This Paper}

In radiological sciences the absorbed dose is relevant, as it refers to the amount of the total energy absorbed by the irradiated tissue. It is measured in joule per kilogram and its measuring unit is the gray (Gy). To take into account the biological effect of a given radiation, the concept of equivalent dose has been introduced. The measurement unit is the Sievert (Sv), defined as the absorbed dose multiplied by a quality factor that weights the radiation-specific biological effects by various sources of radiation. For x-rays, as used in CT, this quality factor is 1 , therefore the equivalent dose equals the absorbed dose and has the same numerical value. 
In order to estimate the biological effect on different tissues, the effective dose is used. This is based on a specific weighting factor that is applied to each tissue. The effective dose is the sum of the weighted equivalent doses of all organs in the body. The measurement unit is also the Sievert (Sv). Thus, the effective dose takes into account both the type of radiation and the type of tissue. Hence, the effective dose makes a comparison possible between various imaging modalities using ionizing radiation. The radiation dose may vary for each CT scanner model and each X-ray tube setting, as for $\mathrm{kVp}$ and $\mathrm{mAs}$, as well as table speed, tube rotation time and pitch (the latter defined as the ratio of the distance that the table advances in one rotation in $\mathrm{mm}$ to the nominal slice thickness in $\mathrm{mm}$ ).

The radiation output of a specific clinical CT examination is commonly presented as the computed tomographic dose index (CTDI) multiplied by the scan length. The CTDI (volume) refers to the absorbed dose in a specific volume (usually in units of mGy) and depends strongly on the patient's anatomy. For reasons of standardized comparison between different scanner designs, the CTDI, 100 represents a basic radiation dose parameter that refers to the radiation exposure measured in an ionization chamber of $100 \mathrm{~mm}$ length.

\section{Biological Effects of Low-Energy X-Rays}

\section{A Brief Survey of Low-Dose Radiation Damage}

In contrast to high-dose radiation, low-dose radiation (below $100 \mathrm{mGy}$ ) may exert a dual genotoxic response in exposed tissues and cells. In mammalian cells, low-dose ionizing radiation causes damage mainly to DNA, as is the case with high-dose radiation. The other phenomenon involves an adaptive protection against the harmful effects and has not been observed at high doses. This response has also been observed as a reaction to endogenous and exogenous toxins other than radiation.

Radiation-induced DNA damage originates from both reactive oxygen species created along the radiation track and direct electron interaction with DNA. The damage to DNA typically causes single-strand breaks, doublestrand breaks (DSBs) and crosslinks. This damage can be repaired on a minute time-scale after the damage has occurred by activation of DNA repair genes. With a delay of several hours, the damaged cells with unrepaired or misrepaired DNA can be removed by apoptosis, necrosis and appropriate immune responses [15]. However, some cells may 'escape' from these protective mechanisms and di- vide, leading to genomic instability and eventually to oncogenic transformation with potential cancer development [16-18].

\section{Biomarkers of Chromosomal Damage}

The micronucleus assay is frequently used as a biomarker for chromosomal damage. It is a low-cost test for the study of damage of the genome and considered as an intermediate endpoint of carcinogenesis due to radiation exposure [19]. Micronuclei in the cell originate from misrepaired, unrepaired DNA lesions or from chromosomal malsegregation due to mitotic malfunction. The resulting formation of micronuclei, whether through chromosomal rearrangement, or altered gene expression (aneuploidy), has been linked to genotoxic events and chromosomal DNA damage [20]. A large epidemiological study has shown that the frequency of a micronucleus in peripheral blood lymphocytes can predict the risk of cancer in humans [21]. For radiological procedures in children with complex congenital heart disease, the micronucleus test has been used as a biomarker for chromosomal damage. A study by Ait-Ali et al. [22] in 59 children showed that the main contribution of dose came from interventional procedures: $84 \%$ and CT $11 \%$, with the median micronucleus value increasing significantly after these procedures from 6 per thousand (before) to 9 per thousand (after); $\mathrm{p}=0.02$.

Another test for chromosomal damage is based upon the phosphorylation of the histone H2AX on serine 139, which was at the time called gamma-H2AX. Initiated by a double-strand break, the phosphorylation of hundreds to thousands of $\mathrm{H} 2 \mathrm{AX}$ molecules form foci at the break sites that can be detected by fluorescence microscopy. This assay has proven to be useful in basic research and clinical studies. For instance, lymphocytes from blood of patients undergoing CT examination or X-ray angiography have shown that individuals repair DSBs to background levels in less than $24 \mathrm{~h}[23,24]$. A recent study by Beels et al. [25] has demonstrated that a CT system operating at higher dose settings causes a significantly higher number of radiation induced gamma-H2AX foci (a 2.1 times higher dose-length product is associated with a 2-3 times higher number of foci). The same study also demonstrated that the number of foci showed a systematic increase versus blood dose. These and other studies [26, 27] confirm that this assay is a useful biodosimetric marker for basic research and human studies.

\section{The Linear Nonthreshold Model}

Epidemiological data from the atomic bomb survivors in Japan has provided risk estimates for moderate to high 
doses above 50-100 mGy. At these doses, there is ample evidence to suggest that excess cancer risk is linearly related to the effective dose. At present there are no epidemiological data that allow for solid estimates below this level and the subject is under continuous debate. However, for practical regulatory purposes, a linear model has been adopted for these low doses. In addition, it is hypothesized that there is no threshold for stochastic effects. This is the linear nonthreshold (LNT) model [28], which has as its starting point that any radiation is potentially harmful and requires some kind of protection. The LNT model starts from an excess cancer risk of 5\% per Sv effective dose. Although the International Committee on Radiation Protection (ICRP) has stated in its publication 103, article 161 in 2007 [29] that this risk factor is not valid to evaluate low-level radiation excess cancer risk of a population, some authors [30,31] used this risk factor and have reported an excess of cancers due to medical diagnostic exposures. Berington de Gonzales et al. [30] estimated that 29,000 future cancers could be related to CT scans performed in the US in 2007. Likewise, Hall and Brenner [31] predicted 750 fatal cancers from CT examinations performed in the UK in 2006.

Various arguments point to an overestimation of the risk by the LNT model. First, carcinogenesis with at least 3 steps of induction, promotion and progression is obviously a nonlinear process. Second, a long-term study among British radiologists showed lower cancer mortality than suggested by extrapolation of the atomic bomb response data [32]. Third, epidemiological studies regarding large populations in geographical areas with high natural background radiation failed to demonstrate any effect [33]. Fourth, at low dose rates, biological systems are stimulated to remove damaged DNA by recruiting homeostatic control systems [34].

By contrast, some findings suggest that there is an underestimation of the risk by the LNT model. First, various in vitro experiments have confirmed radiation responses in neighboring cells, called the bystander effect [35]. Second, genomic instability caused by radiation may cause amplification of chromosomal abnormalities after various cell divisions, although these cells have not been irradiated [36].

Finally, although it is thought that cancer arises from a single hit to nuclear DNA, there is also evidence that non-DNA targets within the cell may be involved $[37,38]$. In addition, hypersensitivity to radiation exists in apparently normal individuals [39]. In these individuals, reactive repair mechanisms and generation of inflammatory cells elicited by radiation damage may be delayed or ab-

Cancer Induction Associated with Pediatric CT sent [40]. Finally, natural background radiation amounts to 2-3 mSv per year, depending on the geographical area. It is therefore conceivable that background radiation also gives rise to carcinogenesis, which would be difficult to differentiate from the effect of a single diagnostic procedure with low-level radiation.

\section{Cancer Risk Estimates at Doses below 100 mSv}

Which risk estimate would be appropriate on the basis of present knowledge? As yet, the public summary (available at www.nap.edu) of the Biological Effect of Ionizing Radiation (BEIR) VII 2006 report endorses the LNT hypothesis but indicates that at doses below $100 \mathrm{mSv}$ 'statistical limitations make it difficult to evaluate cancer risk in humans'. The report relies on a life-time risk of 5 in 100 mortalities from cancer due to an effective dose of $1 \mathrm{~Sv}$. This risk would translate into a risk of $0.05 \%(1$ in 2,000$)$ for an individual who received a dose of $10 \mathrm{mSv}$. In this context, Cardis et al. [41], who conducted a 15-country study following 407,000 radiation workers who received an average dose of $19 \mathrm{mSv}$ for over 20 years, reported an excess all-case mortality, mainly due to an increase of $0.04 \%$ in mortality from all cancers. The excess relative risk rose as the radiation dose increased. It should be noted that the average dose received by these radiation workers is well in the dose range of an average CT examination ranging from $2-20 \mathrm{mSv}$.

Indeed, the previously mentioned study by Ait-Ali et al. [22] demonstrated that the estimated life-time attributable risk of fatal cancer was $0.06 \%$ for a 0 - to 15 -year-old male receiving $7.1 \mathrm{mSv}$ and $0.12 \%$ for a 0 - to 15 -year-old female receiving $9.4 \mathrm{mSv}$. In addition, it was found that the risk is 1.9-2.0 times higher for a child of 1 year than for a 15-year-old individual. These risk estimates were based on a micronucleus assay in children with congenital heart disease, $95 \%$ of whose total collective dose was attributed to diagnostic catheterization (average effective dose $4.6 \mathrm{mSv}$ ), interventional catheterization (average effective dose $6 \mathrm{mSv}$ ) and CT (average effective dose $4 \mathrm{mSv}$ ).

\section{Radiation Risk in Children due to CT}

The above-mentioned 15-country study has added support for the LNT model in the sense that it suggests the absence of a threshold for carcinogenesis. Further support for the no-threshold hypothesis has been provided by Muirhead et al.'s [42] study in which a statistically significant increase in the grouping of malignant neoplasms occurred as the radiation dose increased. The analysis was performed using the National Registry of Radiation Workers in the UK and, as in the 15-country 
study, on a large group of men and women $(\mathrm{n}=174,541)$. Because these two large studies were carried out in workers, no information on the effect of radiation on children has been reported. However, a case-control study (part of the UK Childhood Cancer Study) by Rajaraman et al. [43] showed further evidence of possible excess risk of cancer, even at doses lower than those associated with CT scanning. Exposure of patients in early infancy (0100 days at time of investigation 14 years or younger) to diagnostic radiology (247 procedures in 170 participants) was associated with a slightly elevated risk for all childhood solid cancers (OR 1.16, 0.83-1.62), but the associations were not statistically significant. Nevertheless, an absence of significance should not be interpreted as evidence of a lack of risk. For example, a study by Chodick et al. [44] found an excess risk of CT-related lifetime cancer mortality for patients scanned before age 15 years of age. In a first approximation following the method of risk estimation put forward by Brenner et al. [45], it was suggested that the highest excess risk $(0.52 \%)$ occurred for CT in children under 3 years of age. A recent study by Kuhns et al. [46] used the BEIR VII 2006 report to estimate the lifelong risk for pediatric patients who underwent CT scanning for renal calculus detection. The authors summarized their findings as follows: the ratio of the risk for any abdominal and pelvic cancer due to a CT examination for calculus detection to the risk of a naturally occurring cancer over lifetime of the child is estimated to be 2/1,000 (for children 15 years of age of both genders at the time of examination) and 3/1,000 (for children of both genders, 10 years of age or younger). They estimated the CT radiation dose $(3.6-5.8 \mathrm{mSv})$ to be approximately equivalent to 1-2 years of background radiation. Raelson et al. [47] also used the BEIR VII 2006 report to estimate the stochastic effect of radiation exposure in children ( $0-17$ years of age) who underwent CT scanning for primary neurovascular diagnosis and received an average dose of $35.3 \mathrm{mSv}$. These authors estimated the number of excess cancer cases expected from 100,000 exposed children (321 for males and 388 for females) amounting to an overall increase of about $0.35 \%$ to the lifetime attributable risk of cancer.

The data mentioned above justified the need to apply a 'universal' system to reduce the radiation dose for children and adults. In this respect the ALARA ('As Low As Reasonable Achievable') principle has been widely accepted. It emphasizes the fact that unnecessarily high doses should be avoided. This can be achieved by both judicious use of CT and adjusted, tailored CT techniques [48]. The ALARA principle can only work if there is both appropriate quality assurance regarding the functioning of the CT scanner and specific training for professionals [49]. This task has been addressed by developing a webbased quality improvement program presented as an online tutorial accessible on the Image Gently website that enables radiologists and technologists to perform adequate and safe CT for pediatric patients. For US-based radiologists, this program also complies with new requirements of the American Board of Radiology for maintenance of certification $[50,51]$. The program promotes public awareness and is also meant to educate referring physicians about the potential radiation-associated risks from CT scanning, with an emphasis on pediatric scanning. It stresses the need to justify the examination and make a comparative assessment of $\mathrm{CT}$ on the one hand and ultrasound and/or MRI on the other to avoid unnecessary pediatric radiation exposure.

In 2008, the European Commission issued the European Guidance on Estimating Population Doses from Medical X-Ray Procedures (Radiation Protection No. 154; available at www.ddmed.eu). For pediatric patients, this report gives further significance to a specifically tailored examination protocol using dose reduction features such as the number of CT scans, scan length, field of view, tube voltage, tube current, tube rotation time, beam collimation, table speed, pitch, CTDI (volume) and dose-length product. In addition, patient dose reports, preferably in standard DICOM format, should be documented.

\section{Recent Technical Developments regarding Dose Reduction in Pediatric CT}

Various articles on cancer induction by CT scanning have caused a negative public perception and even led to refusal of the examination by patients or relatives. One article [10] has stated that $1.5-2.0 \%$ of cancers in the US may be caused by ionizing radiation used during CT examination. Other authors, as previously mentioned, have estimated that approximately 29,000 future cancers could be related to CT scans performed in the US in 2007 [30]. Whether true or not, these articles have stimulated the development of new technology platforms to minimize the dose of CT radiation. These efforts, summarized below, are part of an ongoing process to find an appropriate balance between the quality of the produced image and the protection of the patient.

One development involves the modulation of the tube current and adjustment of the intensity of the irradiation to the anatomy of the patient; that is, according to patient attenuation. It is a most practical way of reducing the CT 
dose and this technology can result in a dose reduction of $36-60 \%$ in adults [52]. However, some caution is needed for pediatric imaging with modulated tube current achieved by automatic exposure control, as measurements in a pediatric anthropometric phantom have demonstrated a significant dose increase for salivary glands (28-45\%), bladder (22-51\%) and ovaries (24-70\%) in relation to the high density of the base of the skull and the pelvic bones, respectively [53]. In general, CT parameters for pediatric patients need to be adjusted on the basis of the indication of the study, the age, and the body size, proper positioning of the child, the use of tube filters and tailored pitch.

A newer way of achieving dose is based upon iterative reconstruction. With regard to low dose CT associated with poor noise statistics iterative reconstruction aims to reconstruct an optimal image using iterative algorithms. With advancing computer capabilities this technology has become available as opposed to filtered backprojection. For adults, an abdominal dose reduction of $23-66 \%$ has been reported [54]. A 'blending' of iterative reconstruction and filtered backprojection may lead to a $36 \%$ reduction in radiation dose for a 2 - to 3 -year-old child while adequate diagnostic quality has been maintained [55]. Iterative reconstruction has been successfully used in nuclear medicine where low-photon numbers create noisy images. Briefly, iterative reconstruction uses measured projections to construct an image. In the following step, a 're-projection' process calculates new projections simulating a CT measurement on the basis of the original image, then a corrected image is constructed using the original image and the calculated projections. The calculation proceeds in a loop-wise mode to update the image by moving data back and forth. The final result is enhanced spatial resolution in image areas with higher contrast and reduced noise in areas with low contrast. It is especially useful in CT to enhance images acquired during low radiation dose procedures [56].

The dose reduction techniques have been noticeably increased in cardiology, particularly in children with congenital cardiovascular disease [57]. A significant additional dose reduction can be achieved by ECG triggering ('ECG gating'), which is used to adjust the tube current. Prospective ECG triggering that targets the end-systolic phase is possible in patients with a variable heart rate, roughly between 60 and $110 \mathrm{bpm}$. The end-systolic phase is relatively constant for these heart rates. An algorithm that predicts the 'phase of interest' of the cardiac cycle drives the tube current to $100 \%$, whereas during the remaining phase of the cycle, the current can be reduced

Cancer Induction Associated with Pediatric CT to below $10 \%$. In a series of adult cases prospective ECG gating $(n=57)$ was compared to retrospective ECG gating $(\mathrm{n}=29)$ by DeFrance et al. [58]. The authors found a mean effective dose reduction of $59.2 \%$ using prospective gating compared to retrospective gating with a mean dose of $6.9 \mathrm{mSv}$ for the prospective technique. Only in $0.7 \%$ of the images was the quality judged as noninterpretable. Another study [59] compared both gating methods and reached a reduction of $65 \%$, whereas in $2.6 \%$ (prospective gating) and $0.9 \%$ (retrospective gating), the images could not be interpreted due to low quality. Also, studies by Arnoldi et al. [60] and by Horiguchi et al. [61] mentioned a dose reduction around $60 \%$, but Young et al. [62] stated that the prolonged data acquisition time may cause artifacts in pediatric scanning because breath-hold cannot be maintained. Indeed, a recent study in 20 children who underwent prospective ECG-triggered sequential dual source CT examinations found that in 4 patients breathing artifacts were present [63].

Another significant advance is the recent availability of a 320-slice multidetector CT scanner which allows axial volumetric scanning of a $16-\mathrm{cm}$ long range in a single 0.35 -second rotation with an acquisition configuration of $320 \times 0.5 \mathrm{~mm}$, avoiding any over-ranging and making breath-holding unnecessary [64]. Al-Mousily et al. [65] reported on the use of this scanner in the evaluation of congenital heart disease in 22 infants and young children, 14 of whom were examined without cardiac gating and 8 with prospective gated image acquisition. In the nongated protocol, the effective dose was $1.8 \pm 0.7 \mathrm{mSv}$. The protocol using cardiac gating demonstrated a further dose reduction to $0.8 \pm 0.4 \mathrm{mSv}$. This effective dose, combined with the fact that breath-holding and sedation are not necessary, enables CT to play a greater role in the management of pediatric congenital cardiovascular disease and most likely also in other pediatric disorders.

\section{Epilogue}

Even more than adults, for children the benefit of each imaging study using ionizing radiation should be balanced against the long-term risk of cancer development. According to the widely accepted LNT model, there is no safe dose, but present knowledge about cancer risk due to diagnostic radiation does not give any reason for alarm. However, the effective dose for children who are repeatedly examined may well be above values of $50 \mathrm{mSv}$. This is no longer an effective dose that can be categorized in the low dose range. These doses fall within the realm in 
which increased cancer risk due to ionizing radiation is well-established, and radiologists and referring clinicians should be vigilant about the cumulative risk of radiation exposure.

In this respect, the 'Image Gently' Campaign, an initiative of the Alliance for Radiation Safety in Pediatric Imaging (www.pedrad.org/associations/5364/ig), was launched in early 2008 to urge a significant reduction in the amount of radiation used for pediatric studies. Important advice includes 'scan only when necessary', 'scan only the indicated region', 'involve medical physicists to monitor pediatric CT techniques', and 'involve technologists to optimize scanning.' CT scanners should offer special technology for pediatric imaging [66]. The IAEA Radiation Protection of Patients supports the Image Gently campaign and helps health professionals achieve safer use of radiation for the benefit of children and their parents (www.iaea.org/RPOP/RPOP/Content/ArchivedNews/image-gently).

\section{References}

1 Redberg RF: Cancer risks and radiation exposure from computed tomographic scans: how can we be sure that the benefits outweigh the risks? Arch Intern Med 2009;169: 2049-2050.

-2 Mettler FA Jr, Bhargavan M, Faulkner K, Gilley DB, Gray JE, Ibbott GS, Lipoti JA, Mahesh M, McCrohan JL, Stabin MG, Thomadsen BR, Yoshizumi TT: Radiologic and nuclear medicine studies in the United States and worldwide: frequency, radiation dose, and comparison with other radiation sources - 1950-2007. Radiology 2009;253:520531.

3 Sadetzki S: Excess lifetime cancer mortality risk attributed to radiation exposure from pediatric computed tomography scan. Isr Med Assoc J 2007;9:607-609.

$\checkmark 4$ Mayo JR: Radiation dose issues in longitudinal studies involving computed tomography. Proc Am Thorac Soc 2008;5:934-939.

5 Pantos I, Thalassinou S, Argentos S, Kelekis NL, Panayiotakis G, Efstathopoulos EP: Adult patient radiation doses from non-cardiac CT examinations: a review of published results. Br J Radiol 2011;84:293-303.

6 Dougeni E, Faulkner K, Panayiotakis G: A review of patient dose and optimisation methods in adult and paediatric CT scanning. Eur J Radiol 2012;81:e665-e683.

7 Fazel R, Krumholz HM, Wang Y, Ross JS, Chen J, Ting HH, Shah ND, Nasir K, Einstein AJ, Nallamothu BK: Exposure to lowdose ionizing radiation from medical imaging procedures. N Engl J Med 2009;361:849857.

$\checkmark 8$ Li X, Samei E, Segars WP, Sturgeon GM, Colsher JG, Toncheva G, Yoshizumi TT, Frush DP: Patient-specific radiation dose and cancer risk estimation in CT. II. Application to patients. Med Phys 2011;38:408-419.

-9 Paterson A, Frush DP: Dose reduction in paediatric MDCT: general principles. Clin Radiol 2007;62:507-517.

10 Brenner DJ, Hall EJ: Computed tomography - an increasing source of radiation exposure. N Engl J Med 2007;357:2277-2284.

-11 Donnelly LF, Emery KH, Brody AS, Laor T, Gylys-Morin VM, Anton CG, Thomas SR,
Frush DP: Minimizing radiation dose for pediatric body applications of single-detector helical CT: strategies at a large Children's Hospital. AJR Am J Roentgenol 2001;176: 303-306.

12 Food and Drug Administration: FDA public health notification: reducing radiation risk from computed tomography for pediatric and small adult patients. Pediatr Radiol 2002;32:314-316.

13 Effects of Ionizing Radiation: UNSCEAR 2006, Volume 1; 593, page 138. www.unscear. org/docs/.../2006/07-82087_Report_2006_ Web.pdf.

14 Preston DL, Cullings H, Suyama A, Funamoto S, Nishi N, Soda M, Mabuchi K, Kodama K, Kasagi F, Shore RE: Solid cancer incidence in atomic bomb survivors exposed in utero or as young children. J Natl Cancer Inst 2008; 100:428-436.

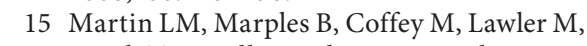
Lynch TH, Hollywood D, Marignol L: DNA mismatch repair and the DNA damage response to ionizing radiation: making sense of apparently conflicting data. Cancer Treat Rev 2010;36:518-527.

16 Barcellos-Hoff MH, Nguyen DH: Radiation carcinogenesis in context: how do irradiated tissues become tumors? Health Phys 200;97: 446-457.

17 Sedelnikova OA, Redon CE, Dickey JS, Nakamura AJ, Georgakilas AG, Bonner WM: Role of oxidatively induced DNA lesions in human pathogenesis. Mutat Res 2010;704: 152-159.

18 Asaithamby A, Hu B, Chen DJ: Unrepaired clustered DNA lesions induce chromosome breakage in human cells. Proc Natl Acad Sci USA 2011;108:8293-8298.

19 Bonassi S, El-Zein R, Bolognesi C, Fenech M: Micronuclei frequency in peripheral blood lymphocytes and cancer risk: evidence from human studies. Mutagenesis 2011;26:93100.

20 Fenech M, Kirsch-Volders M, Natarajan AT, Surralles J, Crott JW, Parry J, Norppa H, Eastmond DA, Tucker JD, Thomas P: Molecular mechanisms of micronucleus, nucleoplasmic bridge and nuclear bud formation in mammalian and human cells. Mutagenesis 2011;26:125-132.

21 Bonassi S, Znaor A, Ceppi M, Lando C, Chang WP, Holland N, Kirsch-Volders M, Zeiger E, Ban S, Barale R, Bigatti MP, Bolognesi C, Cebulska-Wasilewska A, Fabianova E, Fucic A, Hagmar L, Joksic G, Martelli A, Migliore L, Mirkova E, Scarfi M: An increased micronucleus frequency in peripheral blood lymphocytes predicts the risk of cancer in humans. Carcinogenesis 2007;28: 625-631.

22 Ait-Ali L, Andreassi MG, Foffa I, Spadoni I, Vano E, Picano E: Cumulative patient effective dose and acute radiation-induced chromosomal DNA damage in children with congenital heart disease. Heart 2010;96:269-274.

23 Löbrich M, Rief N, Kühne M, Heckmann M, Fleckenstein J, Rübe C, Uder M: In vivo formation and repair of DNA double-strand breaks after computed tomography examinations. Proc Natl Acad Sci USA 2005; 102: 8984-8989.

24 Kuefner MA, Grudzenski S, Schwab SA, Wiederseiner M, Heckmann M, Bautz W, Lobrich M, Uder M: DNA double-strand breaks and their repair in blood lymphocytes of patients undergoing angiographic procedures. Invest Radiol 2009;44:440-446.

25 Beels L, Bacher K, Smeets P, Verstraete K, Vral A, Thierens H: Dose-length product of scanners correlates with DNA damage in patients undergoing contrast CT. Eur J Radiol 2011, Epub ahead of print.

-26 Redon CE, Dickey JS, Bonner WM, Sedelnikova OA: Gamma-H2AX as a biomarker of DNA damage induced by ionizing radiation in human peripheral blood lymphocytes and artificial skin. Adv Space Res 2009;43:11711178.

27 Redon CE, Nakamura AJ, Gouliaeva K, Rahman A, Blakely WF, Bonner WM: The use of gamma-H2AX as a biodosimeter for totalbody radiation exposure in non-human primates. PLoS One 2010;5:e15544.

28 Calabrese EJ: The road to linearity: why linearity at low doses became the basis for carcinogen risk assessment. Arch Toxicol 2009; 83:203-225. 
29 The 2007 Recommendations of the International Commission on Radiological Protection. ICRP publication 103. Ann ICRP 2007; 37:1-332.

-30 Berrington de González A, Mahesh M, Kim KP, Bhargavan M, Lewis R, Mettler F, Land C: Projected cancer risks from computed tomographic scans performed in the United States in 2007. Arch Intern Med 2009;169: 2071-2077.

- 31 Hall EJ, Brenner DJ: Cancer risks from diagnostic radiology. Br J Radiol 2008;81:362378.

-32 Berrington A, Darby SC, Weiss HA, Doll R: 100 years of observation on British radiologists: mortality from cancer and other causes 1897-1997. Br J Radiol 2001;74:507-519.

- 33 Tao Z, Zha Y, Akiba S, Sun Q, Zou J, Li J, Liu Y, Kato H, Sugahara T, Wei L: Cancer mortality in the high background radiation areas of Yangjiang, China during the period between 1979 and 1995. J Radiat Res (Tokyo) 2000;41(suppl):31-41.

34 Pollycove M: Radiobiological basis of lowdose irradiation in prevention and therapy of cancer. Dose Response 2006;27:26-38.

-35 Blyth BJ, Sykes PJ: Radiation-induced bystander effects: what are they, and how relevant are they to human radiation exposures? Radiat Res 2011;176:139-157.

- 36 Suzuki K, Ojima M, Kodama S, Watanabe M: Delayed activation of DNA damage checkpoint and radiation-induced genomic instability. Mutat Res 2006;597:73-77.

- 37 Averbeck D: Non-targeted effects as a paradigm breaking evidence. Mutat Res 2010; 687:7-12.

38 Little MP: Do non-targeted effects increase or decrease low dose risk in relation to the linear-non-threshold (LNT) model? Mutat Res 2010;687:17-27.

- 39 Kato TA, Nagasawa H, Weil MM, Little JB, Bedford JS: Levels of gamma-H2AX Foci after low-dose-rate irradiation reveal a DNA DSB rejoining defect in cells from human ATM heterozygotes in two at families and in another apparently normal individual. Radiat Res 2006;166:443-453.

40 Marples B, Collis SJ: Low-dose hyper-radiosensitivity: past, present, and future. Int $\mathrm{J}$ Radiat Oncol Biol Phys 2008;70:1310-1318.

-41 Cardis E, Vrijheid M, Blettner M, et al: The 15-Country Collaborative Study of Cancer Risk among Radiation Workers in the Nuclear Industry: estimates of radiation-related cancer risks. Radiat Res 2007;167:396-416.

-42 Muirhead CR, O’Hagan JA, Haylock RG, Phillipson MA, Willcock T, Berridge GL, Zhang W: Mortality and cancer incidence following occupational radiation exposure: third analysis of the National Registry for Radiation Workers. Br J Cancer 2009; 100:206-212.

43 Rajaraman P, Simpson J, Neta G, Berrington de Gonzalez A, Ansell P, Linet MS, Ron E, Roman E: Early life exposure to diagnostic radiation and ultrasound scans and risk of childhood cancer: case-control study. BMJ 201;342:d472.
44 Chodick G, Ronckers CM, Shalev V, Ron E: Excess lifetime cancer mortality risk attributable to radiation exposure from computed tomography examinations in children. Isr Med Assoc J 2007;9:584-587.

45 Brenner D, Elliston C, Hall E, Berdon W: Estimated risks of radiation-induced fatal cancer from pediatric CT. AJR Am J Roentgenol 2001;176:289-296.

46 Kuhns LR, Oliver WJ, Christodoulou E, Goodsitt MM: The predicted increased cancer risk associated with a single computed tomography examination for calculus detection in pediatric patients compared with the natural cancer incidence. Pediatr Emerg Care 2011;27:345-350.

47 Raelson CA, Kanal KM, Vavilala MS, Rivara FP, Kim LJ, Stewart BK, Cohen WA: Radiation dose and excess risk of cancer in children undergoing neuroangiography. AJR Am J Roentgenol 2009;193:1621-1628.

-48 Frush DP, Donnelly LF, Rosen NS: Computed tomography and radiation risks: what pediatric health care providers should know. Pediatrics 2003;112:951-957.

49 Reiner BI: Quantifying radiation safety and quality in medical imaging. 1. Creating the infrastructure. J Am Coll Radiol 2009;6: 558-561.

50 Goske MJ, Phillips RR, Mandel K, McLinden D, Racadio JM, Hall S: Image gently: a webbased practice quality improvement program in CT safety for children. AJR Am J Roentgenol 2010;194:1177-1182.

51 Strauss KJ, Goske MJ, Kaste SC, Bulas D, Frush DP, Butler P, Morrison G, Callahan MJ, Applegate KE: Image gently: ten steps you can take to optimize image quality and lower CT dose for pediatric patients. AJR Am J Roentgenol 2010;194:868-873.

52 Söderberg M, Gunnarsson M: Automatic exposure control in computed tomography an evaluation of systems from different manufacturers. Acta Radiol 2010;51:625-634.

53 Brisse HJ, Robilliard M, Savignoni A, Pierrat N, Gaboriaud G, De Rycke Y, Neuenschwander S, Aubert B, Rosenwald JC: Assessment of organ absorbed doses and estimation of effective doses from pediatric anthropomorphic phantom measurements for multi-detector row $\mathrm{CT}$ with and without automatic exposure control. Health Phys 2009; 97:303-314.

54 Prakash P, Kalra MK, Kambadakone AK, Pien H, Hsieh J, Blake MA, Sahani DV: Reducing abdominal CT radiation dose with adaptive statistical iterative reconstruction technique. Invest Radiol 2010;45:202-210.

55 Miéville FA, Gudinchet F, Rizzo E, Ou P, Brunelle F, Bochud FO, Verdun FR: Paediatric cardiac CT examinations: impact of the iterative reconstruction method ASIR on image quality - preliminary findings. Pediatr Radiol 2011;41:1154-1164.
56 Silva AC, Lawder HJ, Hara A, Kujak J, Pavlicek W: Innovations in CT dose reduction strategy: application of the adaptive statistical iterative reconstruction algorithm. AJR Am J Roentgenol 2010;194:191-199.

57 Dillman JR, Hernandez RJ: Role of CT in the evaluation of congenital cardiovascular disease in children. AJR Am J Roentgenol 2009; 192:1219-1231.

58 DeFrance T, Dubois E, Gebow D, Ramirez A, Wolf F, Feuchtner GM: Helical prospective ECG-gating in cardiac computed tomography: radiation dose and image quality. Int J Cardiovasc Imaging 2010;26:99-107.

59 Ko SM, Kim NR, Kim DH, Song MG, Kim $\mathrm{JH}$ : Assessment of image quality and radiation dose in prospective ECG-triggered coronary CT angiography compared with retrospective ECG-gated coronary CT angiography. Int J Cardiovasc Imaging 2010;26: 93-101.

-60 Arnoldi E, Johnson TR, Rist C, Wintersperger BJ, Sommer WH, Becker A, Becker CR, Reiser MF, Nikolaou K: Adequate image quality with reduced radiation dose in prospectively triggered coronary CTA compared with retrospective techniques. Eur Radiol 2009; 19:2147-2155.

61 Horiguchi J, Fujioka C, Kiguchi M, Yamamoto H, Kitagawa T, Kohno S, Ito K: Prospective ECG-triggered axial CT at $140-\mathrm{kV}$ tube voltage improves coronary in-stent restenosis visibility at a lower radiation dose compared with conventional retrospective ECG-gated helical CT. Eur Radiol 2009;19: 2363-2372.

62 Young C, Taylor AM, Owens CM: Paediatric cardiac computed tomography: a review of imaging techniques and radiation dose consideration. Eur Radiol 2011;21:518-529.

63 Pache G, Grohmann J, Bulla S, Arnold R, Stiller B, Schlensak C, Langer M, Blanke P: Prospective electrocardiography-triggered $\mathrm{CT}$ angiography of the great thoracic vessels in infants and toddlers with congenital heart disease: feasibility and image quality. Eur J Radiol 2011;80:e440-e445.

64 Kroft LJ, Roelofs JJ, Geleijns J: Scan time and patient dose for thoracic imaging in neonates and small children using axial volumetric 320-detector row CT compared to helical 64-, 32-, and 16-detector row CT acquisitions. Pediatr Radiol 2010;40:294-300.

65 Al-Mousily F, Shifrin RY, Fricker FJ, Feranec N, Quinn NS, Chandran A: Use of 320-detector computed tomographic angiography for infants and young children with congenital heart disease. Pediatr Cardiol 2011;32: 426-432.

66 Goske MJ, Applegate KE, Bulas D, Butler PF Callahan MJ, Coley BD, Don S, Farley S, Frush DP, Hernanz-Schulman M, Kaste SC, Morrison G, Sidhu M, Strauss KJ, Treves ST: Alliance for radiation safety in pediatric imaging: approaches to promotion and implementation of action on radiation protection for children. Radiat Prot Dosimetry 2011; 147:137-141. 